\title{
Impacts and trade-offs of future land use and land cover change in Scotland: spatial simulation modelling of shared socioeconomic pathways (SSPs) at regional scales
}

\author{
Richard J. Hewitt $^{\mathrm{a}, \mathrm{b}}$, Andrea Baggio Compagnucci ${ }^{\mathrm{a}}$, Marie Castellazzi ${ }^{\mathrm{a}}$, Rob W. Dunford ${ }^{\mathrm{c}}$, \\ Paula A. Harrison ${ }^{d}$, Simona Pedde ${ }^{d, e}$ and Alessandro Gimona ${ }^{a}$ \\ ${ }^{a}$ Information and Computational Sciences Department, James Hutton Institute, \\ Cragiebuckler, Aberdeen AB15 8QH, Scotland, UK (richard.hewitt@hutton.ac.uk, \\ Andrea.Baggio@hutton.ac.uk, Marie.Castellazzi@hutton.ac.uk, \\ alessandro.gimona@hutton.ac.uk) \\ ${ }^{b}$ Observatorio para una Cultura del Territorio, C/ del Duque de Fernán Núñez 2,1, \\ Madrid 28012 \\ 'UKCEH Wallingford, Maclean Building, Crowmarsh Gifford, Wallingford, OX10 8BB, \\ England, UK. (rdunford@ceh.ac.uk) \\ ${ }^{d} U K$ Centre for Ecology \& Hydrology, Lancaster Environment Centre, Bailrigg, \\ Lancaster, LA1 4AH, England, UK (paulaharrison@ceh.ac.uk) \\ ${ }^{e}$ Wageningen University and Research, Department of Environmental Sciences, \\ Droevendaalsesteeg 3, 6708PB Wageningen, The Netherlands
}

(simona.pedde@wur.nl)

June 2020

\begin{abstract}
Current estimates suggest that the world is on track for $\sim 3^{\circ} \mathrm{C}$ of heating relative to pre-industrial levels by 2100 . This is likely to bring great disruption to earth systems, leading to increased natural hazard risks, crop failures, civil unrest and population migration. There is, however, a high degree of uncertainty about the impacts that such events may have on land use and ecosystems in individual countries. Integrated assessment modelling (IAM) of
\end{abstract}


scenarios like the Shared Socioeconomic Pathways (SSPs) offers one way to address this uncertainty, allowing outcomes such as the relative land cover under food production or forestry to be compared for each scenario. However, global and continental-scale IAMs need to be complemented by landscape scale spatial modelling to inform national and regional policy making. In this paper, we demonstrate impacts and trade-offs of future land cover change in Scotland, a UK region with a high degree of political autonomy, using downscaled SSPs from Europe to the national and finally the regional level. Our methods integrate participatory knowledge co-construction approaches with land-use modelling. Firstly, a stakeholder workshop held in November 2018 led to the development of detailed narratives for 5 UK SSPs. Two contrasting UK SSPs, SSP1 (Sustainability), and SSP5 (FossilFuelled Development) were then adapted to the case of Scotland and simulated to the year 2040 using a land use change model (APoLUS). Land use demands for each scenario were quantified based on historical tendencies, narrative information derived from the workshop, and future Scottish Government targets. Results highlight trade-offs between forest cover, grasslands, natural areas including marginal peatlands important for carbon sequestration, and cropland for food production and the drinks industry. We discuss these preliminary findings, highlight key areas of uncertainty and present pathways for future work.

Keywords: participatory scenario planning; land use modelling; climate change impacts; ecosystems; regional scales

\section{INTRODUCTION}

By current estimates, global temperature is likely to increase by around $3^{\circ} \mathrm{C}$ over preindustrial levels by the end of the century (Hausfather and Peters 2020). To respond to this challenge, policy makers need the best available information on the likely consequences, orders of magnitude, and potential impacts on global environments. One widely used approach to obtaining this information is through the Shared Socio-economic Pathways (SSP). SSPs are increasingly widely-adopted as a means of providing plausible and credible socioeconomic boundaries to guide the estimation of impacts (O'Neill et al 2014). Continental-scale versions of the SSPs have been developed for Europe (Kok et al 2019), and are currently being downscaled for the case of the UK (Pedde et al submitted). At the European scale, integrated assessment modelling (IAM) is useful for providing estimates of relative land use in each country under different SSP scenarios, reflecting, e.g. warmer temperatures and differential water availability, increase or decrease of nutrient inputs into 
agriculture, changes in demographics and GDP and projected tendencies of extensification or intensification (Harrison et al 2019). However, to serve the needs of land and environmental managers, qualitative socioeconomic information detailed by the SSPs and quantitative information from IAMs need to be translated into specific impacts on natural and agricultural systems and their implications for societal well-being (partly indicated by ecosystem services). Such information must account for the following key factors.

1. Local circumstances and needs. The information must be spatially explicit - located in real geographical space - rather than obtained as estimates of proportions of overall land use. While it is useful to know, for example, that ecosystems in Scotland are somewhat threatened under SSP5, rather, at the national level, policy makers also need to know what specific ecosystems are threatened and where the most important threats are likely to be.

2. Land system context. The biophysical landscape and historic human activity within it leads to specific land cover formations and adaptations which may not be reflected in continental scale scenarios. For example, while the proportion of forest cover in Britain is generally low, much of the UK's forestry is in Scotland, and is a key part of its landscape and economy. Likewise, Scotland contains internationally significant peatland landscapes whose importance as a store of carbon needs to be reflected in future scenarios.

3. Policy context. Land use policy, both economic (supporting the land-based economy) and environmental (sustainability and responsible stewardship of natural assets) determines to a large extent the specific local adaptations. One such example is the drinks industry, an important part of Scotland's economy, which includes many global premium brands. The viability of this industry, in Scotland, is strongly linked to the agricultural regime (cropland for barley) and the network of policy that supports it. A second example relates to forestry, which current policy specifically targets for expansion.

These factors may interact with drivers at the national and continental scale thus modifying locally the expectations for land cover/use change. In this paper, we describe recent research that aims to provide the information required by policy makers and land-based stakeholders in Scotland to appropriately manage mitigation and adaptation efforts to both direct impacts (e.g. water availability, changes to agricultural systems) and indirect impacts (e.g. food security, demographics, global trade flows and markets). We employed a staged approach that we believe is widely applicable to many national and regional cases. It 
integrates participatory knowledge co-construction to qualitatively downscale European SSPs by producing narratives and change tendencies of different land uses, with spatiallyexplicit land change modeling of two contrasting SSPs to evaluate potential impacts and trade-offs in the land system in Scotland. Our paper is structured as follows. In the next section, we describe our methods, in Section 3 we present our results, and in Section 4 we provide conclusions and recommendations for future work.

\section{METHODS}

\subsection{UK Stakeholder workshop}

The UK stakeholder workshop was designed to link the global and European SSP assumptions at a broader scale with local knowledge and UK-scale dynamics.

The workshop was divided into four main sessions:

1. An interactive plenary designed to brainstorm and identify broad, high-impact and uncertain socioeconomic drivers for the UK. This session led to the clustering of these socioeconomic drivers by category and identification of polarities that characterise the UKrelevant dimensions of the driver's uncertainty for each category.

2. An introduction in plenary of the five narratives of the global/European SSPS and UK trends in Gross Domestic Product and population calculated for each SSP. Stakeholders were then asked to map the uncertainty polarities for each UK-specific driver category, developed in session 1, onto the global/European SSPs.

3. Stakeholders were divided in five breakout groups, one for each UK-SSP, aimed at elaborating a narrative for a single UK-SSP. The groups developed broad lines of development for a range of sectors and synthesised the main interrelationships between drivers within the scenario.

4. Stakeholders discussed trends for eight specific socioeconomic drivers in their individual UK-SSP groups, each group reaching a consensus on the evolution of the semiquantitative trends over time (drawn as a graph) and the rationale for these trends.

The results of the workshop as a whole are time-dependent UK-SSP narratives and tables of semi-quantitative trends in drivers relevant for cross-sectoral assessment. For further information on the UK-SSPs, including the narratives, we refer to Pedde et al. (submitted). Following the workshop, two strongly contrasting narratives - UK-SSP1 and UK-SSP5 - were 
chosen for land use modeling work because the cross-sectoral assumptions they represent have highly contrasting implications for land use (Table 1).

\begin{tabular}{|c|c|c|}
\hline & $\begin{array}{l}\text { UK-SSP1 (sustainability scenario } \\
\text { with harmonisation of land use) }\end{array}$ & $\begin{array}{l}\text { UK-SSP5 (fossil-fuelled development } \\
\text { scenario with exploitation of land- } \\
\text { based resources) }\end{array}$ \\
\hline Agriculture & $\begin{array}{l}\text { - Yields } \uparrow \\
\text { - Food imports } \downarrow \\
\text { - Food production } \downarrow \\
\text { - Fertilizer use } \downarrow \text { to } 0 \text { after } 2070 \text { s } \\
\text { - Replacement of beef and dairy } \\
\text { leads to } \uparrow \% \text { of arable farming } \\
\text { relative to agricultural land }\end{array}$ & $\begin{array}{l}\text { - Yields } \uparrow \\
\text { - Food imports } \uparrow \\
\text { - Food production } \uparrow \\
\text { - Fertilizer use } \uparrow \\
\text { - Looser environmental regulations }\end{array}$ \\
\hline Forestry & - Forestry $\uparrow$ & $\begin{array}{l}\text { - Forestry } \downarrow \text { [different for Scotland, see } \\
\text { below] }\end{array}$ \\
\hline Biodiversity & $\begin{array}{l}\text { - Biodiversity: first } \downarrow \text { and then } \uparrow \\
\text { up 2050s } \\
\text { - Semi-natural habitats in } \\
\text { lowlands and uplands restored }\end{array}$ & $\begin{array}{l}\text { - Biodiversity } \uparrow \text { in uplands, elsewhere } \\
\downarrow \\
\text { - Rewilding } \downarrow\end{array}$ \\
\hline Urban & $\begin{array}{l}\text { - Cities are densely populated and } \\
\text { sustainable }\end{array}$ & - Fast urbanisation and sprawl \\
\hline
\end{tabular}

Table 1: Contrasting cross-sectoral assumptions with important implications for land use from UK-SSPs 1 and 5 (Adapted from Pedde et al. submitted)

\subsection{Land change model development}

To model the effect of drivers of land use change derived from the UK-SSPs on future land use configurations in Scotland, we used a land change modelling application known as APoLUS (Hewitt et al 2015). APoLUS is a freely available script-based framework for the $R$ software environment based on a well-known spatial modeling approach known as cellular automata (CA). In a CA land use model of this type, transition rules are applied to a computerized map of existing land use (urban, agriculture, forest etc) and simulations are then carried out to reveal how the landscape may change at future dates, in response to the input variables used to determine the transition rules. These input variables include cell neighborhood (the degree of attraction of a particular land use to others in its vicinity, and 
the distance at which they are attractive), accessibility (the attractiveness of particular land uses to networks, like roads, rivers or electricity supply), suitability (the biophysical characteristics of particular locations, e.g. terrain slope or land capability for agriculture) and zoning (spatial planning rules and restrictions; e.g. protected areas). The model runs until a fixed number of cells for each land use, known as land use demand, has been allocated. Land use demand is determined by land use growth or decline estimates based on exogenous information from expected tendencies; e.g. population growth affects urban land expansion; agricultural intensification may reduce cropland area, forest policy incentivizes forest growth. The goal of the model is therefore to investigate the spatial allocation of land change, focusing on competition and trade-offs between land use types, rather than to determine the quantity that will be allocated. In this sense, the model is an ideal partner for IAMs like the IMPRESSIONS project Integrated Assessment Platform (IAP2) (Harrison et al 2019), which estimates land use quantities according to socio-economic and environmental assumptions but provides only coarse resolution information about where land use change will occur. IAP2 was developed to explore the implications of combined climatic and socio-economic change at a European Scale. It links ten sectoral models that cover forestry, agriculture, water resources, flooding, urban growth and biodiversity and produces outputs related to sector-based impacts, vulnerability and ecosystem services. The linked framework is designed to facilitate the exploration of the interactions between sectors and to highlight synergies, trade-offs and limits to adaptation under a wide range of possible futures. The model covers the EU27 plus the UK, Norway and Switzerland and operates at a 10 arcmin $\times 10$ arcmin resolution.

For the APoLUS model, data integration and model calibration was carried out following the procedure described in Hewitt et al. (2015). The effect of climate change on land use was simulated using a probability function which substituted the Land Capability for Agriculture (LCA) with Land Capability for Agriculture in 2050 (LCA50) from Brown et al. (2011) using a pseudorandomly generated probability value which tended to 1 as the year 2050 approached. Thus LCA50 most often substituted LCA as simulations approached 2050, but occasionally earlier, reflecting the high uncertainty about the land use impacts of climate change. Land use demand estimation and harmonisation was carried out based on i) IAP2 model disaggregated total \% land area outputs, and ii) land change tendencies identified in stakeholder workshops. Note that while all tendencies were calculated to the year 2050, in line with IAP2, the simulation model was run to 2040, in line with the UK scenario workshop.

\subsection{Land use demand estimation and harmonisation}


Land use demand was estimated for each land use category in 2050 in two ways. Firstly, $a$ top-down approach was applied to translate IAP2 simulations for the two SSPs of total \% land use area estimates disaggregated to the Scotland level into land use demands for 2050. This required some adjustment. First land use categories from IAP2 required harmonisation with those used in APoLUS. The IAP2 land area \% figures for 2050 are derived from SFARMOD (Audsley 1993), which uses agricultural statistics to optimise farm profitability, with crop level data being subsequently aggregated into broad categories. Since these data are aspatial, there is no way to sense-check the figures against total mapped land area in Scotland. As a best approximation, urban land was equated to built-up area in the 2015 land use map, all grassland under IAP2 was equated to semi-natural grassland and improved grassland in the 2015 map, allocated to each of these categories in proportion to their recorded area in the map. Similarly, arable land was matched to horticulture, cereals and potatoes and all forest was assigned to broadleaved and coniferous land use classes. Secondly, we obtained total land use demands for 2050 by taking the mean of the upper and lower bounds for active land use classes translated as described above. Finally, we calculated annual demands for the years 2015-50 assuming linear growth or decline of land uses to meet the total percentages thus estimated for 2050.

The second approach to land use demand estimation for each actively modelled land use category in 2050 was through a bottom-up approach, in which information from the stakeholder workshop was translated into qualitative estimates of land change. The main resource for this work was the so-called STEEP (social, technology, economy, environment, policy) table of drivers (a categorisation common in scenario development - Hunt et al. 2012), with change to key drivers denoted on a seven point scale, from very strong decrease $(-,-,-)$ to very strong increase $(+,+,+)$, with " 0 " indicating no change. This information was combined with stakeholders' semi-quantitative assessment of trends transcribed from the workshop sessions, recorded using a numerical value - very strong decrease $(-3)$ to very strong increase $(+3)$.

\begin{tabular}{|c|c|c|c|c|c|c|c|c|c|}
\hline Landuse & $\begin{array}{l}\text { Area } \\
2015 \\
(\%)\end{array}$ & $\begin{array}{l}\text { IAP2- } \\
\text { SSP1 } \\
2050 \\
(\%)\end{array}$ & $\begin{array}{l}\text { IAP2- } \\
\text { SSP1 \% } \\
\text { change }\end{array}$ & $\begin{array}{l}\text { SW- } \\
\text { SSP1 } \\
2050 \\
(\%)\end{array}$ & $\begin{array}{l}\text { SW- } \\
\text { SSP1 \% } \\
\text { change }\end{array}$ & $\begin{array}{l}\text { IAP2- } \\
\text { SSP5 } \\
2050 \\
(\%)\end{array}$ & $\begin{array}{l}\text { IAP2- } \\
\text { SSP5 } \\
\% \\
\text { change }\end{array}$ & $\begin{array}{l}\text { SW- } \\
\text { SSP5 } \\
2050 \\
(\%)\end{array}$ & $\begin{array}{l}\text { SW- } \\
\text { SSP5 \% } \\
\text { change }\end{array}$ \\
\hline SnG & 16.5 & 19.6 & - & - & - & 13.2 & - & - & - \\
\hline Mountain & 24.6 & 24.6 & - & - & - & 24.6 & - & - & - \\
\hline
\end{tabular}




\begin{tabular}{|l|l|l|l|l|l|l|l|l|l|}
\hline heath & & & & & & & & & \\
\hline Bog & 9.4 & 9.4 & - & - & - & 9.4 & - & - & - \\
\hline Built-up & 1.7 & 2.8 & $+65 \%$ & 1.8 & $+6 \%$ & 3.1 & $+80 \%$ & 1.8 & $+6 \%$ \\
\hline $\begin{array}{l}\text { Improved } \\
\text { grassland }\end{array}$ & 18.5 & 21.9 & $+18 \%$ & 17.8 & & 14.8 & $-20 \%$ & 18.2 & \\
\hline $\begin{array}{l}\text { Horticultur } \\
\text { e }\end{array}$ & 2.0 & 0.6 & $-70 \%$ & 2.2 & & 1.0 & $-50 \%$ & 1.3 & \\
\hline Cereals & 6.1 & 1.8 & $-70 \%$ & 6.6 & $+8 \%$ & 3.1 & $-49 \%$ & 6.0 & $-2 \%$ \\
\hline Potatoes & 0.3 & 0.1 & $-67 \%$ & 0.3 & $0 \%$ & 0.2 & $-33 \%$ & 0.3 & $0 \%$ \\
\hline $\begin{array}{l}\text { Broadleave } \\
\text { d }\end{array}$ & 4.0 & 1.4 & $-65 \%$ & 10.3 & & 5.3 & $+33 \%$ & 6.7 & \\
\hline Coniferous & 12.9 & 4.6 & $-64 \%$ & 15.6 & $+21 \%$ & 17.3 & $+34 \%$ & 19.4 & $+50 \%$ \\
\hline Salt water & 0.6 & 0.6 & - & 0.6 & - & 0.6 & - & 0.6 & - \\
\hline $\begin{array}{l}\text { Fresh } \\
\text { water }\end{array}$ & 2.1 & 2.1 & & 2.1 & & 2.1 & & 2.1 & - \\
\hline Coastal & 1.2 & 1.2 & - & 1.2 & - & 1.2 & - & 1.2 & - \\
\hline
\end{tabular}

Table 2: Land use demands from IAP2 and from stakeholder workshops (SW) for the two modelled scenarios, obtained by the procedures described in Section 2.2.3. " that the land use class was not actively modelled (see Hewitt et al 2015, p.10). SnG - semi natural grassland

The trends estimated by workshop participants were used in conjunction with recent past tendencies calculated from CORINE land cover (CLC) maps 2006-2018. The annual historic tendency (whether increase or decrease) was not adjusted for "no change", doubled for small increases ("+" or "1"), tripled for larger increases ("+,+" or " 2 ") and multiplied by five for very large increases $(“+,+,+$ "), - and likewise for decreases - except where the narrative clearly required a different multiplier. Change tendencies for forestry were not recorded by workshop participants. Scottish forestry strategy up to 2070 is, however, clearly set down in a policy paper (SG 2019) which specifies, among other, more detailed targets, that forest cover should occupy 21\% of Scotland by 2032 (up from around 17\% in 2015). For SSP1 total forestry area under these targets comprised $70 \%$ new broadleaved woodland, and $30 \%$ new coniferous plantation, reflecting the priorities of sustainability under this scenario, while for SSP5 this figure was reversed, with the $70 \%$ of new planting expected to come from conifers and $30 \%$ from broadleaved woodland under this economic growth-oriented scenario. 


\section{RESULTS AND DISCUSSION}

\subsection{Top-down land use demand estimation using IAP2}

The limitations of this preliminary approximation approach were immediately clear from the figures, which suggested changes that seem improbable for Scotland (Table 2). For instance, under SSP5, the area occupied by built-up land would almost double by 2050 ( $80 \%-2.3 \%$ annual increase), and even in SSP1, a supposed sustainability scenario, would increase by $65 \%$ (1.9\% annual increase). This can be viewed in the light of the $0.001 \%$ annual increase in urban area in Scotland recorded by CORINE land cover (CLC) between 2006 and 2018. The $18 \%$ increases (SSP1) and 20\% decreases (SSP5) in improved grassland are just about imaginable over $\sim 35$ years (ca. $0.5 \%$ and $0.6 \%$ increase annually, respectively) but seem unlikely when compared with the $0.021 \%$ increase in pasture recorded by CLC in Scotland over the 12 years between 2006 and 2018, an annual increase of just 0.02\%. In SSP1, the decline of total forest cover in Scotland to $6 \%$ of the total land area (currently around 17\%) would require a loss of $11 \%$ of the total forest area, 148000 ha of forested land, approximately $90 \%$ of the size of the Isle of Skye. This seems unlikely in an environmental sustainability scenario like SSP1, given the limited competition between forest and agriculture in Scotland. Also, these figures indicate a decline in arable land ( $-70 \%$ in SSP1 overall and $\sim-50 \%$ in SSP5 overall) that is greater than the greatest known decline in arable land ever recorded in the British Isles - the reduction from 6 million ha to 3.5 million ha recorded in England between 1870 and 1939 (Green 1976). Finally, in many cases the tendencies estimated from IAP2 did not match the tendencies estimated from the stakeholder workshop, especially for SSP1 (Table 2). This was a very useful exercise, showing that further work is needed in downscaling from continental to national and then regional scale. Given the implausibility of the top-down figures estimated using the IAP2 data, the model was not run using these demands.

\subsection{Bottom-up land use demand estimation using historic change tendencies, stakeholder knowledge and policy targets}

Using stakeholder knowledge to determine land change tendencies works well when the development of the land use model is an explicit part of the participatory process. Workshop participants - who are sectoral experts - can be supplied with figures for historical land change, and can be involved in identifying the land use classes and land use dynamics for which tendencies are required. In different situations, such as that 
documented here, where the land use modelling work was developed separately to the participatory workshop process, it can be difficult to fully harmonise information collected from stakeholders. Future participatory workshops are planned, so there is still an opportunity to make greater use of spatial data (e.g. participatory mapping) to guide activities that are expected to lead to spatially explicit outcomes. By applying increases or decreases recorded by stakeholders over a historical baseline, plausible land use demands can be estimated that are bounded by real land system constraints. The size of the increases is quite uncertain - this could be addressed by varying these estimates up or down and evaluating the land use change impacts of scenario ensembles rather than single snapshots.

\subsection{Impacts and trade-offs of projected land use}

By using the bottom-up demand estimation process described above some provisional results were obtained for each of the two SSPs (Fig 1).

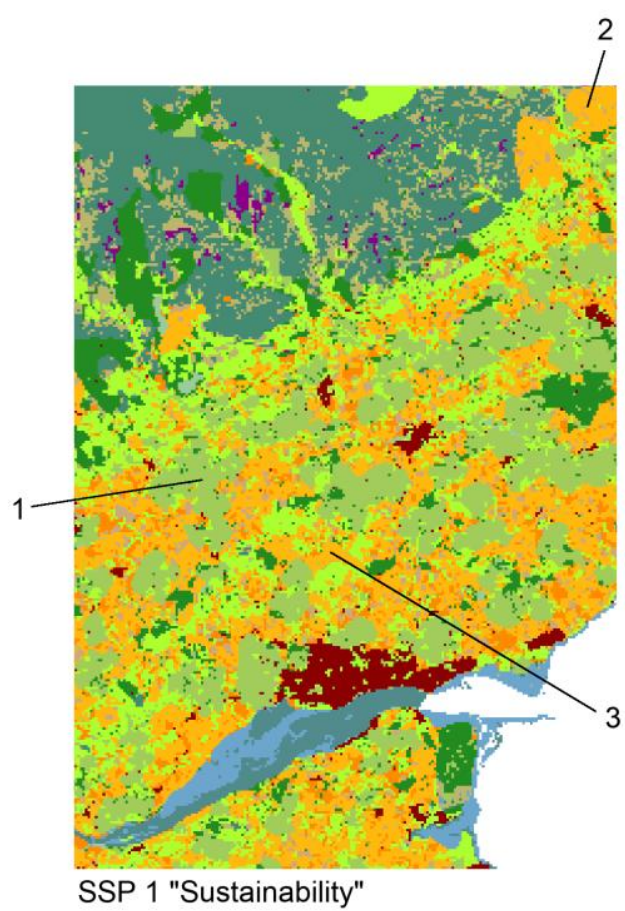

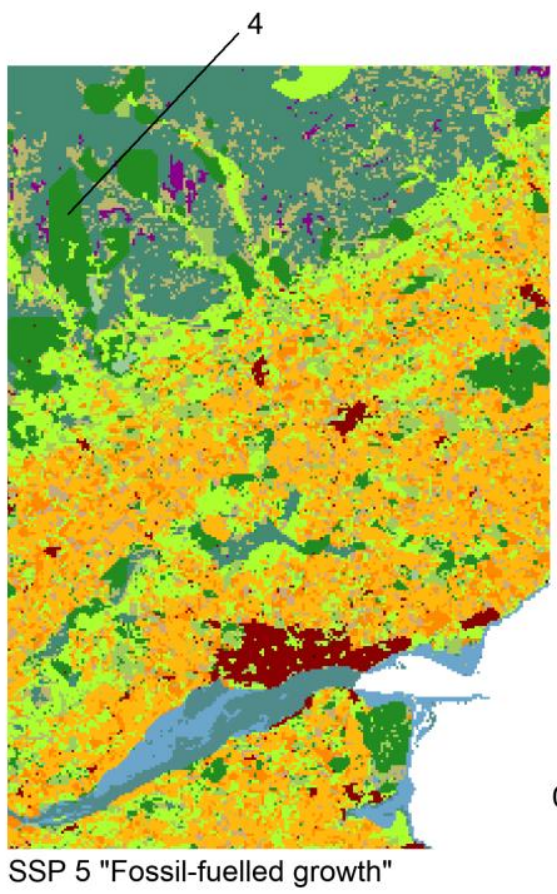

SSP 5 "Fossil-fuelled growth"
Legend

$\square$ Semi-natural grassland

Mountain heath

Bog

Built up areas and gardens

$\square$ Improved grassland

$\square$ Horticulture

$\square$ Cereals

$\square$ Potatoes

Broadleaved woodland

Coniferous woodland

Saltwater

$\square$ Freshwater

Coastal

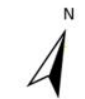

$\begin{array}{lllll}0 & 5 & 10 & 15 & 20 \\ \mathbf{k m}\end{array}$

Figure 1: Land use simulations (2040) for both scenarios. Numbers are referenced in the text, e.g. [1].

Scotland's forestry targets (SG) are very ambitious (Table 2). In Fig 1, which shows the area around Dundee and the Firth of Tay, the possible consequences of prioritising broadleaved expansion to make up $70 \%$ of the targets can be seen in the left hand panel (SSP1). Large areas of broadleaved woodland have emerged around existing forest stands [1], displacing arable cropland onto the hilly margins [2] (which become more suitable for arable over time 
- see Section 2.2), occupying bog [2] and heathland not subject to special protection [3] (i.e. on shallow organic soils) None of these dynamics are evident in SSP5, where the forestry targets are the same, but achieved by expanding coniferous forest [4], rather than broadleaved, to $70 \%$ of the new targets. Aside from the different proportion of forestry classes, the main differences in land change dynamics between SSP1 and SSP5 relate to agriculture. In SSP1, both yields and area under arable were expected to increase, with arable replacing grassland. This is because of strong mitigation of the negative impacts of livestock farming (emissions, poor energy and nutrient input/output ratio) together with the need for more cropland to supply localised food networks. The simulation model (Fig 1) suggests that competition between arable cropland, which is expanding, and broadleaved woodland, which is also increasing, could potentially lead to sub-optimal land use and loss of natural areas. This trade-off was not obvious a priori. Identification of this important trade-off between forestry and cropland under a sustainability scenario shows the value of this kind of modelling approach for land use policy.

In SSP5, arable land was projected to decline (Table 1). Improved grassland also declines, as a response to reduced profitability following the withdrawal or reduction of agricultural subsidies under a more market-oriented post-Brexit agricultural policy. These factors, combined with the prioritization of the more commercially-oriented coniferous woodland to achieve Scottish government policy targets mean that there is a lot more space in the lowlands, and potentially, fewer unpleasant choices to be made between tree planting and food production.

\subsection{Conclusions and Recommendations}

The work presented here has provided a crucial test-bed for integrating continental scale information on socioeconomic pathways with land use dynamics at the scale of the national and sub-national region. Both levels of information are needed to guide land use policy under rapid climate change. IAMs like IAP2 are essential for providing estimates of changes to land systems according to socio-economic and environmental assumptions provide by global scenario frameworks like the SSPs. However, spatial allocation models like APoLUS are necessary for understanding where such changes are likely to occur, what the consequences are likely to be (impacts and trade-offs), and to provide recommendations for land managers on the ground. 
Two approaches to this key task were tested. For the first of these (top-down approach), we tried to match land use categories from the SFARMOD component of IAP2 with categories in the APoLUS land use model and derive demand tendencies from the \% differences between the projected IAP2 figures and the land use map for 2015. This approach produced figures that seemed unrealistic in a Scotland context, and moreover, differed from stakeholders' interpretation of the same SSPs. The likely explanation is major differences in the way land use is understood between the IAP2 and APoLUS models, such as the way land uses are quantified - in IAP2, for example, land use demands are calculated at the European scale though competition with other regions - as well as the reference data used, and the thematic classification of land use types. Where the IAP2 tendencies differed from stakeholders' interpretations, this may be due to a mismatch between continental scale assumptions and the UK context. Further integration work is clearly required here, for example, by: 1) adjusting the SFARMOD module to account for spatial constraints, 2) harmonizing land use categories between the models; 3) extracting more plausible land change tendencies by using IAP2 to simulate both 2015 and 2050. Beyond these technical considerations, there is a need to understand why the assumptions in the IAP2 model differed widely from stakeholders' interpretations of the same tendencies for the UK. This could be the subject of a future stakeholder workshop activity.

For the second method (bottom-up approach), we calculated future land use demand for the two scenarios by using stakeholders' interpretations of key land change tendencies as multipliers for annual units of change determined from past land use maps (2006-18). This approach ensures that future land use demand is at least bounded within plausible orders of magnitude derived from the land system under study. However, such an approach does risk over-constraining possible extreme outcomes that are outside previous experience. Where detail on Scotland was lacking, i.e. in the case of forestry, we used Scottish government policy objectives instead. Projections made with the APoLUS model to 2040 illustrate important trade-offs between different land uses. The results highlight possible unintended consequences, especially in the case of a sustainability scenario (SSP1) which looks to increase woodland in line with stated targets primarily by expanding broadleaved woodland in its most suitable locations. In the simulation, this led to competition between new broadleaved woodland and arable land. But since SSP1 envisaged arable land expansion and grassland decline, APoLUS solved the conflict by moving some arable land to (newly suitable) former grassland areas on the upland fringe. This indicates a potentially significant conflict between arable and forestry, as well as suggesting a more likely future pathway for 
grazing land than reversion to a semi-natural state. It can also be considered that the policy targets for forestry may be unrealistically ambitious ${ }^{1}$.

This short paper provides an illustration of the difficulties of integrating models of different types together, well-summarized by Voinov and Shugart's (2013) concept of an "integronster", a monstrous beast that is joined together, Frankenstein-like, from a clutter of mismatched pieces. More work is clearly needed if individual country level information on land change is to be usefully obtained from continental-scale integrated assessment platforms, especially those that rely on profit optimisation assumptions to estimate overall shares of land use. For smoother integration of stakeholder information from participatory workshops, participatory mapping activities could be introduced, including identification of key change dynamics and relation to land uses, participatory classification of land use maps, and participatory cartography of impacts and outcomes reflected in the SSPs.

\section{ACKNOWLEDGMENTS}

The work reported here was funded by the Rural \& Environment Science \& Analytical Services Division of the Scottish Government and the Natural Environment Research Council award number NE/R016429/1 as part of the UK-SCAPE programme delivering National Capability. We gratefully acknowledge the efforts of workshop participants in unravelling the drivers of change for the UK SSPS.

\section{REFERENCES}

Audsley, E., 1993. Labour, machinery and cropping planning. In: Annevelink, E., Oving, R.K., Vos, H.W. (Eds.), Farm planning. Labour and labour conditions. Computers in agricultural management, Proceedings of the XXV CIOSTACIGR V Congress, Wageningen, Netherlands, pp. 83-88.

Brown, I., Poggio, L., Gimona, A., \& Castellazzi, M. (2011). Climate change, drought risk and land capability for agriculture: implications for land use in Scotland. Regional Environmental Change, 11(3), 503-518.

Green, F. H. W. (1976). Recent changes in land use and treatment. Geographical Journal, 1226.

\footnotetext{
${ }^{1}$ Even more ambitious targets have recently been proposed and will be addressed as part of future work.
} 
Harrison, P. A., Dunford, R. W., Holman, I. P., Cojocaru, G., Madsen, M. S., Chen, P. Y., ... \& Sandars, D. (2019). Differences between low-end and high-end climate change impacts in Europe across multiple sectors. Regional environmental change, 19(3), 695-709.

Hausfather, Z., \& Peters, G. P. (2020). Emissions-the 'business as usual' story is misleading. Nature 577, 618-620.

Hewitt, R., de Boer, C., Pacheco, J., Hernández Jiménez, V., Alonso, P., Román, L., \& van der Meulen, M. (2015). APoLUS model full system documentation. Project Report for EU FP7 Programme COMPLEX Project (deliverable 3.5).

Hunt, D. V., Lombardi, D. R., Atkinson, S., Barber, A. R., Barnes, M., Boyko, C. T., ... \& Caserio, M. (2012). Scenario archetypes: Converging rather than diverging themes. Sustainability, 4(4), 740-772.

Kok, K., Pedde, S., Gramberger, M., Harrison, P. A., \& Holman, I. P. (2019). New European socio-economic scenarios for climate change research: operationalising concepts to extend the shared socio-economic pathways. Regional environmental change, 19(3), 643-654.

O’Neill, B. C., Kriegler, E., Riahi, K., Ebi, K. L., Hallegatte, S., Carter, T. R., ... \& van Vuuren, D. P. (2014). A new scenario framework for climate change research: the concept of shared socioeconomic pathways. Climatic change, 122(3), 387-400.

Pedde, S. et al (submitted) Enriching the Shared Socioeconomic Pathways to co-create consistent multi-sector scenarios for the UK. Science of the Total Environment.

Scottish Government (2019). Scotland's Forestry Strategy 2019-2029. Available at: https://www.gov.scot/publications/scotlands-forestry-strategy-20192029/ Accessed: June 2020. The Scottish Government, Edinburgh

Voinov, A., \& Shugart, H. H. (2013). 'Integronsters', integral and integrated modeling. Environmental Modelling \& Software, 39, 149-158. 